Institute of $\mathbf{F}_{\text {ood and }} \mathbf{A g r i c u l t u r a l}_{\mathbf{S}} \mathbf{S}_{\text {ciences }}$

Hazardous Household Substances: Alternatives That Are Relatively Free of Toxic Effects ${ }^{1}$

\author{
Marie Hammer ${ }^{2}$
}

Many people believe that hazardous or toxic chemicals are found only in industries that manufacture plastics, pesticides, pharmaceuticals or automobiles. However, a wide range of products that we use in our homes contains chemicals that fit the definition of hazardous or toxic. Hazardous products line our kitchen, bath, utility and garage shelves. In most cases the concentration of the chemical products found in the home are much lower than the concentration of those found in the workplace. However, the potential for exposure to chemicals from household products in the home does exist.

\section{What Can We Do?}

Misuse or improper disposal of these hazardous products can pose a threat to your health. Longterm or cumulative problems, such as contamination of drain fields and septic systems, as well as surface and groundwater can also occur.
To decrease exposure to pollutants and produce less hazardous household waste, consideration should be given to using alternatives that contain chemicals that are relatively free of toxic effects.

The U.S. Environmental Protection Agency (EPA) defines a substance as hazardous if it is flammable, can react or explode when mixed with other substances, is corrosive or toxic.

\section{Why Do We Use Potentially Hazardous Products?}

Time and some convenience are the primary reasons. In days past, the sink was scrubbed with baking soda. Extra effort was needed to maintain a stain free sink. Wood floors were cleaned with oil and vinegar/or just mineral oil. This eliminated the need for wax, but required more work. Today, most households contain safe substances relatively free of toxic effects that can be combined to do the job currently being done by a hazardous product.

1. This document is FCS 3149, one of a series of the Department of Family, Youth and Community Sciences, Florida Cooperative Extension Service, Institute of Food and Agricultural Sciences, University of Florida. Publication date: July 2002. First published: June 1988. Revised: July 2002 Please visit the EDIS Web site at http://edis.ifas.ufl.edu

2. Written by Marie Hammer, former Professor, Housing/Home Environment, Department of Family, Youth and Community Sciences, Cooperative Extension Service, Institute of Food and Agricultural Sciences, University of Florida, Gainesville, 32611 and reviewed by Nayda I. Torres, Professor, Family and Consumer Economics, Department of Family, Youth and Community Sciences, Cooperative Extension Service, Institute of Food and Agricultural Sciences, University of Florida and Dale Dorman, Extension Housing and Environment Specialist - Emeritus, Cooperative Extension Service, University of Georgia.

The use of trade names in this publication is solely for the purpose of providing specific information. UF/IFAS does not guarantee or warranty the products named, and references to them in this publication does not signify our approval to the exclusion of other products of suitable composition. The Cooperative Extension Service assumes no responsibility and disclaims any liability for any injury or damage resulting from the use or effect of any product or information appearing in this document. 


\section{Is It Hazardous?}

Check the label. Many household products used for household cleaning, car care or yard care can be toxic, corrosive, flammable or reactive. All of the designations are considered hazardous. The signal words on the label are "CAUTION," "WARNING" or "DANGER." "CAUTION" indicates a lower level of toxicity and "DANGER" is the highest level of toxicity.

\section{Household Cleaners}

Many common household cleaning products contain dangerous ingredients such as caustics or solvents, which when used, stored or disposed of improperly, could threaten your family's health or damage the environment. Caustic chemicals such as those found in oven cleaners (lye, sodium hydroxide), drain cleaners, scouring powders or bleach can cause burns and severe damage to the skin and eyes.

Solvents are fast-drying substances that dissolve another substance. Inhalation of these vapors or accidental drinking can be harmful or even fatal. Long-term exposure to some solvents may cause liver and kidney problems, birth defects, central nervous system disorders and cancer.

Furniture polish, silver cleaner, paint remover and wood floor wax contain solvents.

\section{Waste Disposal}

Be aware of the hazards indicated on the label before using the product. Carefully follow directions concerning use, storage and disposal. In most cases there will be no specific directions for disposal of the "left over" product. The best disposal route for hazardous products is to use them up according to the directions, or share with a friend. If you need to separate any portion of the product from its original container, be sure to duplicate the label in its entirety and attach it to the new container.

\section{Your Alternatives}

You can reduce handling, use and disposal hazards associated with dangerous household products by substituting safer alternatives. Some of these alternatives are as simple as immediately mopping up spills with water or club soda. Full strength vinegar or lemon juice applied to rust stains or hard water deposits will fade and perhaps eliminate the stain. In some cases these options may require more effort to get the desired results.

Reducing the amount of hazardous products you purchase not only saves money, but also eliminates the threat of accidental exposure and pollution of the environment. You may decide to use latex water base paint, scrub your sink with baking soda, or spray your plants with a mixture of pepper water and garlic. Once you understand the basic substitutes, formulas and procedures, you can make your own decisions about tradeoffs. Fortunately, most households harbor the basic ingredients for safer substitutes for most of these hazardous household materials.

To help you get started the following alternatives to household hazardous products are provided. These alternatives are relatively free of toxic effects.

\section{Relatively Toxic-Free Household Alternatives}

See Table 1 for places to purchase products mentioned in this publication.

\section{Air Fresheners}

- Open the window or use an exhaust fan -- or both.

- Use the air conditioner to dry the air and keep odors down.

- Sprinkle baking soda in odor-producing areas. 
- Place an open box of baking soda in the refrigerator to absorb food odors.

\section{Aluminum Cleaners}

- Scour badly abraded aluminum vessels with whiting (Calcium carbonate, found in paint stores) and soap jelly (recipe given in General Purpose Cleaners section). Use very fine steel wool.

- Brighten a discolored aluminum pan by boiling it in one of the following solutions until the discoloration disappears:

- 1 tablespoon of vinegar to 1 quart water

- 2 teaspoonfuls of cream of tartar to 1 quart water.

\section{Bathroom Cleaners/Disinfectants}

- Mildew and other stains can be removed from grout with a solution of $1 / 2$ cup of bleach and 1 cup water. Let stand 5 minutes and rinse with clear water.

- Wash with washing soda (sodium carbonate)

- Wash with borax (sodium borate)

\section{Brass and Copper Cleaners}

- Make a paste of:

- 1 pint soap jelly (see General Purpose Cleaners)

- 1 cup whiting

- 1 teaspoon household ammonia

Add whiting and ammonia to soap jelly before it congeals, and beat together. After using the paste, wash articles in hot suds, rinse and dry.

- Tarnished copper also can be cleaned with salt dissolved in hot white cider or lemon juice.
- Brass with an antique finish can be polished with boiled linseed oil or lemon oil.

\section{Carpet and Rug Cleaner}

- Clean the carpet on a sunny day with the windows opened to speed up drying. Don't soak the carpet -- it may mildew.

- Test the shampoo first on an inconspicuous area to check for possible discoloration.

- Use a mix of baking soda with water.

- Prepare a liquid detergent and boiling water solution (see Upholstery Cleaners section). Rub the foam in $4 \times 4$ foot sections. Continue the same process as for upholstery.

\section{Ceramic Tile Cleaner}

- Prepare a mixture of 2 tablespoons of trisodium phosphate (TSP) and 1 gallon of water. Apply to tile and grout with a brush or cloth. Mop up dirty water with sponge or cloth. Needs no rinsing unless higher concentration of TSP is used for heavy cleaning.

\section{Drain Cleaners}

To keep drains clean:

- Cover drains with screens.

- Flush pipes with $1 / 2$ pound of washing soda in 2 cups boiling water, then rinse. Do this once a month.

To unclog drains:

- Mix 1 cup each of baking soda, salt and white vinegar. Wait 15 minutes. Pour in drain and flush thoroughly with boiling water. Use a rubber plumber's snake if drain is seriously clogged. 


\section{Floor Polish (Liquid)}

- $1 / 4$ cup paraffin and 2 quarts mineral oil. Melt paraffin in a double boiler. Stir in mineral oil. Transfer to bottles and label.

\section{Furniture Polish}

- Dust with cloths that gather dust rather than scatter it. Make dust cloths by putting cloths in a tin container or jar in which a few drops of oil or wax have been placed. Cover tightly and leave overnight. The cloths will absorb just enough oil or wax to remove dust and polish the surface at the same time.

- Use lemon oil and beeswax.

- Use beeswax and olive oil.

- Mix 2 teaspoons lemon oil and 1 pint mineral oil in a spray bottle.

- Mix 1 tablespoon mild soap powder, 1 quart water, 1 tablespoon household ammonia, and 2 tablespoons boiled linseed oil or a good furniture polish.

- Mix equal portions of denatured alcohol, strained fresh lemon juice (not canned or frozen), olive oil or boiled linseed oil, and gum turpentine. Shake mixture each time before using. This polish keeps indefinitely.

\section{General Purpose Cleaners}

- Vinegar with salt and water.

- Vinegar mixed with water.

- Baking soda on a damp sponge (rinse with water and polish to shine).

- Most soap pads (for example, SOS pads).

- Baking soda -- rub with $1 / 2$ lemon dipped in sodium bicarbonate.
2 tablespoons of ammonia, 2 tablespoons liquid detergent, 1 quart warm water.

- Soap jelly (used in other formulas). To make, dissolve 1 cup of shaved soap or soap flakes in 1 quart of boiling water. When entirely melted or dissolved, pour into a wide mouth jar. Let stand in a cool place until it jells.

\section{General Purpose Metal Polish}

- $\quad 1 / 2$ cup household ammonia, $1 / 2$ cup denatured alcohol, 1 cup diatomaceous earth. Mix ammonia and alcohol. Stir in the diatomaceous earth. Add water to make a creamy mixture. Store in bottle which has been labeled, and shake before using.

\section{Iron Cleaner}

- Boil the item in soda water (sodium bicarbonate solution) for a few minutes to clean. Remove rust from iron with steel wool or scouring powder.

- Before storing untreated iron or steel pots and pans, coat with saltless fat or oil, wrap in paper and store in a dry place.

\section{Oven Cleaners}

- Wipe away grease and spills after using the oven. Wipe away charred spills with a nonmetallic bristle brush. If the oven is wiped out after each use, there will not be a need to use harsh chemicals for cleaning.

- To remove baked on grease and spills, scrub with a baking soda, salt and water paste. Or sprinkle with dry baking soda, then scrub with a damp cloth after 5 minutes. (Do not let baking soda touch wires or heating elements.) Scour racks and burner inserts with steel wool.

\section{Painted Surfaces}

- To prevent streaking, wash walls by starting at the baseboard and working upward. If soiled water runs down on the clean surface, clean it 
up immediately. Gloss enamel-painted walls are easier to clean than flat-painted walls because they will withstand stronger washing solutions.

- For general cleaning, use a mixture of soap jelly (see General Purpose Cleaners) or liquid detergent and warm water. Add enough water to make light suds. Dust all painted surfaces thoroughly before washing, then wash with a soft cloth dipped in the cleaning solution and wrung out. Rinse well and then dry with a soft cloth. Wash only a small area at a time.

- Whiting paste will remove fingerprints and clean heavily soiled places. Make it by mixing four parts of whiting with one part soap jelly. Keep it in a small jar. Apply with a soft cloth, rubbing lightly, then rinse.

\section{Silver}

- Pour water into an aluminum or enameled pan with aluminum foil covering the bottom of the pan. Fill to a depth of 2 to 3 inches (enough to cover silver with water). Add 1 teaspoon baking soda, 1 teaspoon salt, and heat until water boils. Add tarnished silver and boil 3 minutes. Remove silver, wash in soapy water, and polish dry. (Not for use on silver jewelry or flatware with hollow handles).

\section{Toilet Bowl Cleaner}

- Clean with borax and lemon juice.

- Pour $1 / 2$ cup liquid chlorine bleach into toilet bowl. Let stand for at least 30 minutes, then scrub with a long-handled brush and flush. Remember, never mix ammonia and bleach.

- Salt and water.

\section{Upholstery Cleaner}

- Mix $1 / 2$ cup mild liquid dishwashing detergent with 1 pint boiling water. Let cool. Whip into a thick foam using an electric mixer. Pretest a small area before proceeding. Apply the foam to the fabric with a damp sponge. Wipe off the suds with a clean cloth. To rinse, add 1 cup of white vinegar to 1 gallon of lukewarm water. Rinse well using as little liquid as possible and change the water often. Put pressure on a clean white towel to remove the moisture (do not rub).

\section{Window and Mirror Cleaners}

- Remove surface soil with a paper towel or soft cloth. Then apply the cleaning liquid with a cloth or sponge. Rub dry and polish with a newspaper or cloth.

- On windows rub the inside in one direction and the outside in another to determine which side the streaks are on. Avoid spilling the cleaner on painted or varnished woodwork because it can damage the finish.

- Add 2 tablespoons of vinegar to 1 quart water. Apply with a wadded-up newspaper.

- Mix 3 tablespoons of ammonia, 1 tablespoon white vinegar and $3 / 4$ cup water in a clean spray bottle.

- Mix $1 / 4$ cup cornstarch, $1 / 2$ cup ammonia, and 1 cup vinegar in a jar. Wear gloves, if necessary, because vinegar is a mild acid. It will remove rust or lime deposits on the outside of windows.

\section{General Rules for Managing Toxic Household Products}

- Select the least toxic products for your home.

- Buy only as much as you will use.

- Read the label. It will list ingredients, instructions for use, storage, and disposal; and hazards associated with use.

- Avoid aerosol spray cans whenever possible. Buy liquid, paste or powder forms of products. 
- Dispose of toxic waste as recommended. Call your County Department of Environmental Services for specific information about Amnesty Days and other disposal options.

\section{Preventive Measures}

- An aggressive home maintenance plan will reduce the amount of cleaning products and hazardous household products needed in the home. For example, roaches and other insects are discouraged by good housekeeping practices.

- Store food in sealed containers.

- Wipe up spills.

- Bathe pets frequently to eliminate fleas.

- Put a piece of screen over drains to catch food particles or hair.

- Avoid hard-to-clean baked-on stains in the oven by wiping up after each use and/or use liners to catch spills.

- Air out the house occasionally to avoid the use of chemical air fresheners.

\section{Safety Considerations}

- Never mix chlorine bleach with any other cleaning agent, such as ammonia or vinegar. It may create toxic fumes.

- Store all cleaning solutions out of reach of children.

- To avoid accidental poisoning, never transfer a product to a container that once held food or drink.

- Be sure that each container has a label.

- Mix cleaning solutions in a well-ventilated area.

- Clean up after using toxic substances.
- Never smoke or eat when handling hazardous materials.

- Keep the container closed. Harmful fumes may escape from an open container.

\section{Resources}

Table 1. Where to purchase products mentioned in this publication.

\begin{tabular}{|c|c|}
\hline Cleaning Product & Where to Purchase \\
\hline Ammonia & $\begin{array}{l}\text { Retail } \\
\text { Supermarket/Pharmacy }\end{array}$ \\
\hline $\begin{array}{l}\text { Baking Soda } \\
\text { (sodium bicarbonate) }\end{array}$ & $\begin{array}{l}\text { Retail } \\
\text { Supermarket/Pharmacy }\end{array}$ \\
\hline Boiled linseed oil & Hardware Store \\
\hline Borax & $\begin{array}{l}\text { Retail } \\
\text { Supermarket/Pharmacy }\end{array}$ \\
\hline Cream of tartar & $\begin{array}{l}\text { Retail } \\
\text { Supermarket/Pharmacy }\end{array}$ \\
\hline Denatured alcohol & Hardware Store/Pharmacy \\
\hline Diatomaceous earth & $\begin{array}{l}\text { Pool Chemical Supply } \\
\text { Company }\end{array}$ \\
\hline Fuller's earth & Ceramic Shop/Pharmacy \\
\hline Gum turpentine & Hardware Store/Pharmacy \\
\hline Salt (sodium chloride) & $\begin{array}{l}\text { Retail } \\
\text { Supermarket/Pharmacy }\end{array}$ \\
\hline Trisodium phosphate & Hardware Store/Pharmacy \\
\hline Vinegar & Retail Supermarket \\
\hline $\begin{array}{l}\text { Washing soda } \\
\text { (sodium carbonate) }\end{array}$ & Retail Supermarket \\
\hline Whiting & Paint Store \\
\hline
\end{tabular}

For more information about hazardous household substances:

Chemical Information Center, toll free, 1-800-262-8200, 8:00 AM - 9:00 PM. Information about proper use and possible side effects of chemical ingredients in cleaners, household products, pesticides and fuels. 
Chemical Referral Center, c/o Chemical Manufacturers Association, 2501 M Street, N.W., Washington, DC 20037 (202-887-1318). A brochure providing information on services provided free.

Disposal: Do It Right -- Managing Household Wastes. The Household Products Disposal Council, 1625 Eye Street, NW, Suite 500, Washington, DC 20006. This is an information service established through a trade association, the Chemical Specialties Manufacturers Association. Both a four-fold pamphlet and a 16-page booklet are available free of charge.

Florida, State of the Environment. Florida Department of Environmental Regulation, 2600 Blair Stone Road, Tallahassee, FL 32399-2400 (904-488-9334). Free.

Household Hazardous Waste: Solving the Disposal Dilemma. Gina Purin, Golden Health Empire Health Planning Center, 210021 st Street, Sacramento, CA 95818.

Hazardous Wastes from Homes. Florida Department of Environmental Regulation, 2600 Blair Stone Road, Tallahassee, FL 32399-2400; or order from Enterprise for Education, 1320A Santa Monica Mall, Santa Monica, CA 91401. Single copies are $\$ 2.75$ plus $\$ 1.50$ for postage and handling. Discounts available on quantity orders.

Hazardous Household Waste, What You Should and Shouldn't Do. Water Pollution Control Federation, 601 Wyeth Street, Alexandria, VA 22314-1994 (703-684-2438). A colorful, easyto-read chart that establishes the most effective means of disposing of household waste.
House Dangerous. Ellen J. Greenfield, Foreword by Ralph Nader, Vintage Books, a division of Random House, New York, NY.

Know Your Chemicals, Alternatives and Precautions. Florida Department of Environmental Regulation, 2600 Blair Stone Road, Tallahassee, FL 32399-2400.

Making the Switch -- Alternatives to Using Toxic Chemicals in the Home. Golden Empire Health Planning Center, 210021 st Street, Sacramento, CA 95818 (916-731-5050).

Nontoxic and Natural: How to Avoid Dangerous Everyday Products and Buy or Make Safe Ones. Debra Lynn Dadd. Nontoxic Lifestyles, Inc., Box 210019, San Francisco, CA 94121.

For more information, contact the Department of Environmental Regulation, County Health Department or the County Cooperative Extension Office. Your Extension office can provide you with a variety of printed materials on Managing Household Hazardous Substances.

The University of Florida Cooperative Extension Service assumes no responsibility and disclaims any liability for any injury or damaging resulting from use or effect of any product or information appearing in this section. No endorsements are intended or implied. 